\title{
Evaluation of the capillary electrophoresis method for measurement of immunoglobulin concentration in ewe colostrum
}

\author{
V. Lopreiato, ${ }^{\star} \dagger$ C. Ceniti, ${ }^{\star} \dagger$ F. Trimboli, ${ }^{,} \dagger^{1}$ E. Fratto, $\dagger$ M. Marotta, $†$ D. Britti, ${ }^{*} \dagger$ and V. M. Morittu${ }^{*} \dagger$ \\ *Department of Health Science, and \\ †Interdepartmental Services Centre of Veterinary for Human and Animal Health, Magna Græcia University of Catanzaro, Catanzaro, Italy, 88100
}

\begin{abstract}
Capillary electrophoresis (CE) is a technique routinely used in clinical laboratories that allows the separation and quantification of blood serum proteins in a rapid, precise, accurate, and inexpensive manner. Recently, CE has been proposed to separate and measure colostral proteins, but an evaluation of the agreement between $\mathrm{CE}$ and radial immunodiffusion (RID) method, currently used to quantify IgG in colostrum, is still lacking. The purpose of this study was to test the ability of a CE instrument, normally used in blood serum protein analysis, to realize the correct quantification of total Ig concentration in ewe colostrum, using RID assay as reference. Colostrum samples $(\mathrm{n}=68)$ were collected from 35 multiparous Sarda ewes at first milking $(\mathrm{n}=33)$ and at $24 \mathrm{~h}$ postpartum $(\mathrm{n}=35)$. The mean \pm standard deviation of IgG concentration measured by RID and whey colostrum total Ig concentration measured by $\mathrm{CE}$ were $54.76 \pm 41.82 \mathrm{~g} / \mathrm{L}$ and 54.70 $\pm 41.43 \mathrm{~g} / \mathrm{L}$, respectively. Lin's concordance correlation coefficient $(\mathrm{r}=0.993 ; 95 \%$ confidence interval $=0.989$ to 0.996 ) and linear regression analysis results (RID $\left.=1.0022 \mathrm{CE}-0.063 ; \mathrm{R}^{2}=0.986\right)$ showed an excellent agreement between these 2 methods. Bland-Altman analysis confirmed that $\mathrm{CE}$ method can be a suitable alternative to RID: the mean of the differences between $\mathrm{CE}$ and RID was $-0.055 \pm 4.95 \mathrm{~g} / \mathrm{L}$ (95\% confidence interval $=-1.25$ to $1.14 \mathrm{~g} / \mathrm{L})$ and the agreement limits were -9.75 to $9.60 \mathrm{~g} / \mathrm{L}$ (low limit $95 \%$ confidence interval $=-11.82$ to $-7.68 \mathrm{~g} / \mathrm{L}$; high limit $95 \%$ confidence interval $=7.57$ to $11.72 \mathrm{~g} / \mathrm{L}$ ). In conclusion, the current study indicates that $\mathrm{CE}$ method may be a reliable tool for the quantification of the total Ig concentration in ewe colostrum.
\end{abstract}

Key words: colostrum, immunoglobulin, capillary electrophoresis, radial immunodiffusion

Received November 9, 2016.

Accepted April 21, 2017.

${ }^{1}$ Corresponding author: trimboli@unicz.it

\section{INTRODUCTION}

In the last years, the importance of sheep dairy farms has increased worldwide, especially in developing countries (Lérias et al., 2014). To increase milk production, lambs are reared by artificial feeding systems providing them colostrum and milk replacer (Demirören et al., 1995). The early intake of colostrum in ruminant newborns is fundamental to transfer them an adequate quantity of IgG that provides passive immunity and to increase their survival rate (Constant et al., 1994; Stelwagen et al., 2009). Some authors proposed the bovine colostrum as alternative source to feed lambs (Quigley et al., 2002; Moretti et al., 2010), but lambs fed with this colostrum source run the risk of developing anemia (Winter and Clarkson, 1992; Winter, 2011; Ruby et al., 2012). It is preferable to feed lambs with colostrum by creating a high-quality ewe colostrum bank.

To date, the radial immunodiffusion (RID) method is the gold standard method for measurement of $\mathrm{IgG}$ concentration in blood serum. Moreover, RID assay is currently used to determine IgG concentration also in milk and colostrum even if it is not a reference method for colostral IgG determination. Nevertheless, RID is expensive, laborious for analysis of a large number of samples, and highly time consuming (18 to $24 \mathrm{~h}$ to determine the results), so it is not a method eligible for the routine analysis of $\operatorname{IgG}$ concentration. Due to the high resolving power and unique selectivity in separation and characterization of proteins (Zhu et al., 1990), capillary electrophoresis (CE) is routinely used in the clinical laboratories to separate and quantify blood serum proteins. In the past years, CE has been successfully used to analyze milk whey proteins and has been demonstrated to be rapid and easy to use (Cifuentes et al., 1993; Cartoni et al., 1999) and requires a very small volume of sample. Recently, Ceniti et al. (2016) employed a CE instrument to separate ewe whey colostrum proteins and successively identified on an electrophoretogram the fraction corresponding to total Ig. The authors conclude by proposing the use of $\mathrm{CE}$ to measure total Ig concentration in ewe colostrum. 
Therefore, before accepting CE method as alternative to others currently employed in ovine colostral Ig quantification, it is necessary to demonstrate its interchangeability. At this end, the aim of the present study was to assess the level of agreement between $\mathrm{CE}$ and RID method in quantifying the Ig concentration in ewe colostrum.

On the basis that IgG represent the major class of colostral Ig in ruminants, reaching $94 \%$ of the total Ig content in the ovine colostrum (Lérias et al., 2014), Bland-Altman analysis was performed to evaluate the agreement between the 2 methods.

\section{MATERIALS AND METHODS}

\section{Colostrum Sample Collection}

Between April and July 2014, colostrum samples from 35 multiparous Sarda ewes were collected at first milking within $2 \mathrm{~h}$ after lambing (first milking, $\mathrm{n}=33$ ) and at $24 \mathrm{~h}$ after parturition $(\mathrm{n}=35)$. The farm employee collected a volume of $50 \mathrm{~mL}$ of colostrum from each animal by hand-milking into plastic test tubes. Samples were inverted 8 to 10 times to thoroughly mix the colostrum for an accurate homogenization, and an aliquot of each colostrum sample (approximately $5 \mathrm{~mL}$ ) was transferred into another plastic test tube for measurements of IgG content by RID. Samples were labeled with animal identification number and date of collection and frozen at $-20^{\circ} \mathrm{C}$. Samples were then transferred to the Magna Græcia University of Catanzaro, where they were stored at $-80^{\circ} \mathrm{C}$ until analysis.

\section{Radial Immunodiffusion Analysis}

Colostrum samples were thawed at $4^{\circ} \mathrm{C}$ and then warmed for $15 \mathrm{~min}$ in a water bath at $40^{\circ} \mathrm{C}$ and gently mixed to ensure good homogeneity. The IgG concentration was assessed by RID technique using the Sheep and Goat IgG IDRing Test (IDBiotech, ImmunoDiffusion Biotechnologies SARL, Issoire, France).

Briefly, $50 \mu \mathrm{L}$ of colostrum were diluted in $4,950 \mu \mathrm{L}$ of physiological solution (dilution 1) and then $50 \mu \mathrm{L}$ of dilution 1 were diluted in $450 \mu \mathrm{L}$ of SRID buffer $1 \mathrm{X}$ delivered by the manufacturer. The plate wells were filled with $15 \mu \mathrm{L}$ of sample, reserving 4 wells to the corresponding standards delivered by the manufacturer. A total of 12 plates was used. Plates were placed in a humid box and incubated for 18 to $22 \mathrm{~h}$ at $37^{\circ} \mathrm{C}$. Diffusion was stopped by adding $5 \mathrm{~mL}$ of freshly prepared $2 \%$ acid acetic solution (code no. 401424, Carlo Erba Reagents S.r.l., Cornaredo, Milano, Italy) and leaving the plates for $1 \mathrm{~min}$ at room temperature. Plates were rinsed twice with deionized water, and after adding
$5 \mathrm{~mL}$ of deionized water, they were incubated for 15 min at room temperature. The resulting ring diameters were measured using the IDRing Viewer system (IDBiotech, ImmunoDiffusion Biotechnologies SARL). The standard curve for the single plate was established by plotting the square root concentration on the abscissa against the diameters for each standard on the ordinate $\left(\mathrm{R}^{2}\right.$ of each plate was between 0.98 and 0.99 ), and $\operatorname{IgG}$ concentration was calculated by linear regression.

\section{Whey Colostrum Preparation and Total Whey Protein Determination}

Colostrum samples were thawed at room temperature and gently mixed to ensure a good homogeneity. Then, rennet solution (with 100\% chymosin; 200 international milk clotting units $/ \mathrm{mL}$, water, sodium chloride, sodium benzoate, and chymosin; Hansen Standard Chy-Max Plus 200, Chr. Hansen, Hoersholm, Denmark) was added and samples were incubated for $30 \mathrm{~min}$ at $37^{\circ} \mathrm{C}$. After 30 min from rennet addition, clot was manually cut with 2 orthogonal vertical cuts using a stainless steel spatula. Once each clot was cut, samples were centrifuged at $2,500 \times g$ for $30 \mathrm{~min}$ at $4^{\circ} \mathrm{C}$ and whey was collected and filtered using a $0.45-\mu \mathrm{m}$ syringe filter (Minisart, Sartorius Stedim Biotech GmbH, Göttingen, Germany).

Total whey proteins (TWP) were quantified by Biuret assay using commercial reagents on a Dimension EXL analyzer (Siemens Healthcare Diagnostics s.r.l., Milan, Italy) according to the manufacturer's instructions (www.siemens.com/diagnostics).

\section{Capillary Electrophoresis Analysis}

The CE analysis was performed using a Minicap capillary electrophoresis system (Sebia, Lisses, France). The fully automated instrument performs whey colostrum proteins separation using a $17 \mathrm{~cm}(16 \mathrm{~cm}$ to detection point $) \times 25 \mu \mathrm{m}$ i.d. coated fused-silica capillary with an applied voltage of $7.8 \mathrm{kV}$ at $35.5^{\circ} \mathrm{C}$. The instrument requires a dead volume of sample approximately to $200 \mu \mathrm{L}$, but the sample injected is about 1 $\mathrm{nL}$. The injection is carried out at the anode by using a pressure (hydrodynamic injection) of 2,000 $\mathrm{Pa}$ for 1 $\mathrm{s}$. The electrophoresis buffer is a $150 \mathrm{~m} M$ borate buffer $\mathrm{pH} 9.9 \pm 0.5$ (Sebia). Time migration is $238 \mathrm{~s}$ and the system performs 2 tests simultaneously using 2 capillaries that work at the same time. The protein detection at the cathode extremity takes place by reading the absorbance at $200 \mathrm{~nm}$.

After manual selection of the total Ig fraction area (Ceniti et al., 2016) on the electrophoretogram, the instrument software calculates the percentage of total 
Table 1. Descriptive statistics of colostrum data used in analyses

\begin{tabular}{|c|c|c|c|c|c|}
\hline Item & Mean & $\mathrm{SD}$ & $95 \% \mathrm{CI}$ & Minimum & Maximum \\
\hline Total $(\mathrm{n}=68)$ & 54.76 & 41.82 & $44.63-64.88$ & 3.81 & 163.40 \\
\hline \multicolumn{6}{|l|}{ Whey colostrum Ig by $\mathrm{CE}^{2}(\mathrm{~g} / \mathrm{L})$} \\
\hline Total $(\mathrm{n}=68)$ & 54.70 & 41.43 & $44.67-64.72$ & 3.80 & 165.10 \\
\hline First milking $(\mathrm{n}=33)$ & 82.07 & 40.63 & $67.66-96.58$ & 15.60 & 165.10 \\
\hline
\end{tabular}

${ }^{1}$ Radial immunodiffusion assay.

${ }^{2}$ Capillary electrophoresis.

Ig area with respect to the total curve area. Once the TWP value $(\mathrm{g} / \mathrm{L})$ of the sample is inserted, the instrument software provides the value of total Ig concentration $(\mathrm{g} / \mathrm{L})$ applying the following formula:

$$
\text { total } \operatorname{Ig}(\mathrm{g} / \mathrm{L})=\operatorname{Ig} \text { area }(\%) \times \operatorname{TWP}(\mathrm{g} / \mathrm{L}) \text {. }
$$

\section{Statistical Analysis}

The Univariate procedure of SAS (version 9.3, SAS Institute Inc., Cary, NC) was used to determine the following descriptive statistics for the distribution of the values $(\mathrm{n}=68)$ obtained by the 2 assays: mean, standard deviation, $95 \%$ confidence interval of the mean, minimum, and maximum value. Lin's concordance correlation coefficient (CCC; Lin, 1989) was calculated by SAS to evaluate the precision and accuracy of CE against the RID method. This coefficient may vary from 0 to 1 , where 1 indicates perfect fit. In addition, linear regression analysis between $\mathrm{CE}$ and RID data

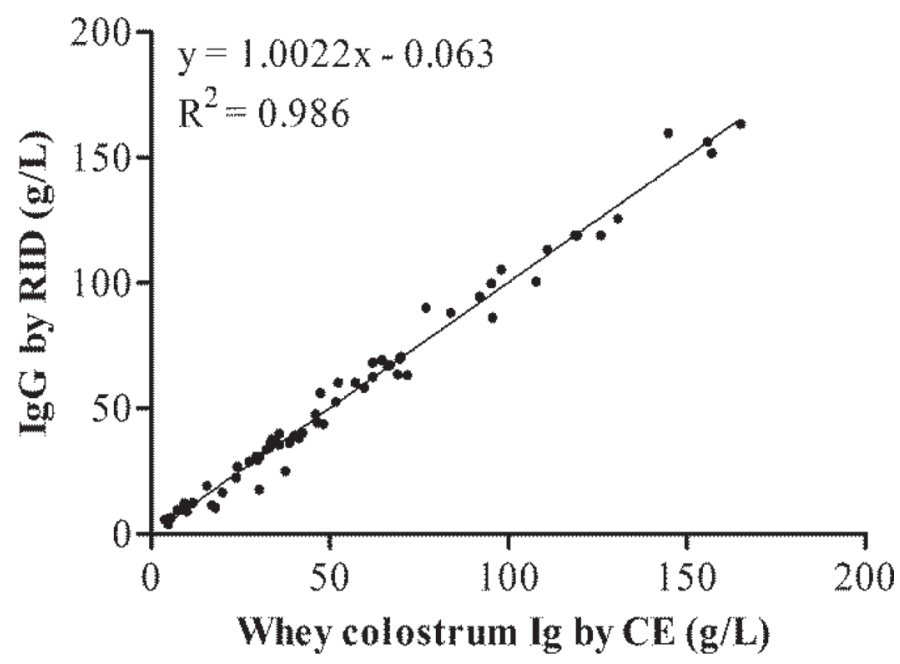

Figure 1. Relationship between whey colostrum Ig concentration by capillary electrophoresis (CE) method and IgG concentration by radial immunodiffusion (RID) assay of colostrum samples from Sarda ewes. was performed by PROC REG procedure of SAS. Statistical significance was declared at $P<0.05$.

The bias between the 2 methods was estimated according to Bland and Altman (1986) using SAS software by calculating the mean difference, the standard deviation of the differences, and the limits of agreement (mean difference $\pm 1.96 \mathrm{SD}$ of the differences). Furthermore, the $95 \%$ confidence interval of the mean difference and of the agreement limits were also calculated to illustrate the magnitude of the systematic difference and to estimate the size of the possible sampling error, respectively. A 1-sample $t$-test was applied to establish if the mean value of differences was significantly different from $0(P<0.05)$, indicating existence of fixed bias. In addition, to evaluate the existence of proportional bias, the regression analysis by PROC REG of SAS software was performed between the differences in measurements (CE - RID) and the average of Ig by CE and RID methods.

\section{RESULTS}

Descriptive statistics of the IgG values obtained by RID and of the total Ig values obtained by CE are shown in Table 1. The Ig concentrations measured by RID and CE ranged from 3.81 to $163.40 \mathrm{~g} / \mathrm{L}$ and from 3.80 to $165.10 \mathrm{~g} / \mathrm{L}$, respectively.

Lin's CCC between RID and CE values was 0.993 $(95 \% \mathrm{CI}=0.989$ to 0.996$)$, and the linear regression analysis showed a strong relationship between these 2 methods $\left(\mathrm{RID}=1.0022 \mathrm{CE}-0.063 ; \mathrm{R}^{2}=0.986\right.$ and $P<0.0001 ;$ Figure 1) with the intercept not different from $0(P=0.95)$ and the slope close to 1 .

The results of the Bland-Altman analysis are shown in Figure $2 \mathrm{a}$ and $2 \mathrm{~b}$. The mean difference \pm standard deviation between CE and RID results was $-0.055 \pm$ $4.95 \mathrm{~g} / \mathrm{L}(95 \% \mathrm{CI}=-1.25$ to 1.14$)$ and the limits of agreement carried out were -9.75 to $9.60 \mathrm{~g} / \mathrm{L}$ (low limit $95 \% \mathrm{CI}=-11.82$ to $-7.68 \mathrm{~g} / \mathrm{L}$; high limit $95 \% \mathrm{CI}$ $=7.57$ to $11.72 \mathrm{~g} / \mathrm{L}$; Figure 2a). This mean difference did not differ from $0(P=0.93)$. Moreover, the linear 
regression analysis between differences (dependent variable) and average of Ig concentration by CE and RID (independent variable) did not show proportional bias $\left(\mathrm{y}=-0.009 \mathrm{x}+0.46 ; \mathrm{R}^{2}=0.006 ; P=0.52\right)$ (Figure $2 b)$.

\section{DISCUSSION}

In the current study, we evaluated the use of a $\mathrm{CE}$ instrument, routinely applied for blood serum proteins
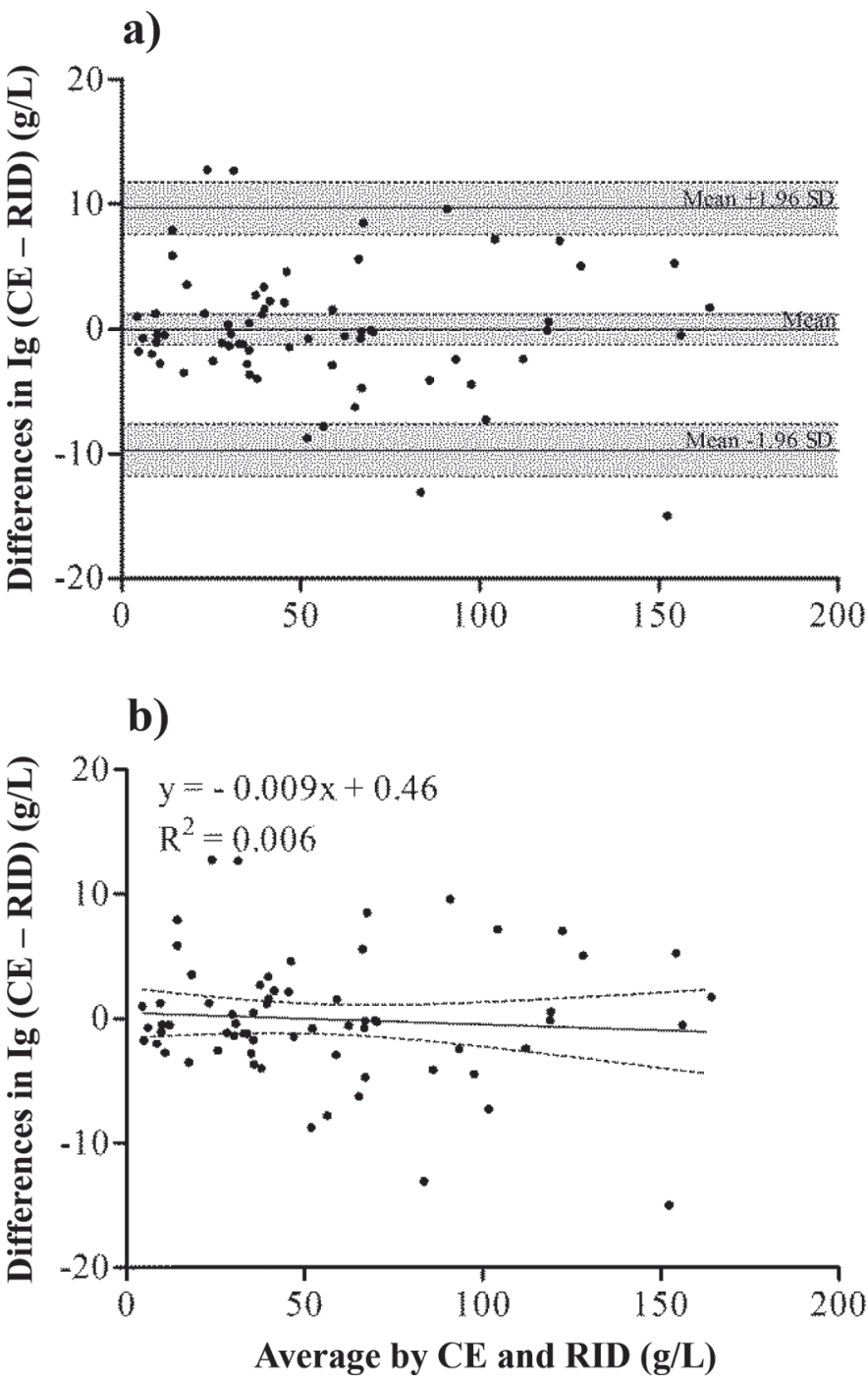

Figure 2. (a) Bland-Altman plot of agreement between radial immunodiffusion (RID) and capillary electrophoresis (CE). The differences between $\mathrm{CE}$ and RID concentration $(\mathrm{g} / \mathrm{L})$ are plotted against the average of CE and RID values. Solid lines represent the mean of differences and the limits of agreement. Dashed lines represent $95 \% \mathrm{CI}$ of the mean difference and of the limits of agreement. (b) Relationship between the differences and average of Ig concentration by $\mathrm{CE}$ and RID. The solid line represents the linear regression curve, and dashed lines represent the $95 \%$ CI of linear regression. analysis, to quantify colostral total Ig by comparing $\mathrm{CE}$ values with IgG concentrations determined by RID.

Although CE measures total Ig concentration, we have observed that the average of total Ig concentration measured in first milking samples (Table 1) was very similar to values referred to $\operatorname{IgG}$ concentration reported by al-Sabbagh et al. (1995; 72 to $85 \mathrm{~g}$ of $\mathrm{IgG} / \mathrm{L}$ ) and Swanson et al. (2008; $82.1 \mathrm{~g}$ of $\mathrm{IgG} / \mathrm{L})$ both determinate by RID assay. The reliability of the $\mathrm{CE}$ was confirmed by the high value of Lin's CCC and by the regression analysis results (Figure 1) that showed a strong relationship between Ig concentration values provided by $\mathrm{CE}$ and RID. These results indicated a high agreement between the 2 methods. This outcome was confirmed by Bland-Altman analysis: the mean differences between $\mathrm{CE}$ and RID values did not differ significantly from 0 , indicating that there was not a fixed bias. In addition, regression analysis between difference and average of Ig values by $\mathrm{CE}$ and RID did not show proportional bias. Indeed, no trend of mean differences related to the increasing of Ig concentration values indicates that the 2 methods agree equally across the entire range of concentrations tested. Moreover, the colostrum samples analyzed in this study covered a wide range of Ig concentrations (Table 1). This is a desirable feature when the 2 methods are compared, as it allows exploration of the agreement over the full range of measurements (Bland and Altman, 2003).

As stated by Bland and Altman (2003), the limits of agreement should be evaluated on the basis of clinical, not statistical, criteria. Unfortunately, to our knowledge, the recommendation about the Ig concentration cut-off defining a good-quality ewe colostrum has not been declared (Hernández-Castellano et al., 2015).

Some authors reported that lambs should receive at least 28 to $30 \mathrm{~g}$ of IgG in the first 18 to $24 \mathrm{~h}$ from birth to achieve values of serum $\operatorname{IgG}$ concentration higher than $15 \mathrm{mg} / \mathrm{mL}$ in the first $48 \mathrm{~h}$ of life (Loste et al., 2008; Alves et al., 2015) ensuring them correct passive transfer (Massimini et al., 2006). In light of this, we can consider the values of agreement limits found in this study compatible with a reliable quantification of total Ig in ewe colostrum, although a definitive evaluation will be expressed when Ig concentration cut-off defining a good quality ewe colostrum will be proposed.

\section{CONCLUSIONS}

The CE method tested in the present research performs an unbiased quantification of total Ig content in ewe colostrum when compared with the RID assay, indicating the interchangeability of RID with CE. The CE method has also the advantage of being a reliable, rapid, inexpensive, and simple system for measuring 
ewe colostrum Ig. Furthermore, the rapid quantification of colostral Ig concentration is useful to define a good-quality colostrum that can be efficiently stored in a colostrum bank. This allows a successful colostrum management program, ensuring continuous availability of good-quality colostrum to newborn lambs.

\section{ACKNOWLEDGMENTS}

Support was provided by the Interdepartment Services Centre of Veterinary for Human and Animal Health, Magna Graecia University of Catanzaro di Catanzaro, Catanzaro, Italy.

\section{REFERENCES}

al-Sabbagh, T. A., L. V. Swanson, and J. M. Thompson. 1995. The effect of ewe body condition at lambing on colostral immunoglobulin G concentration and lamb performance. J. Anim. Sci. 73:28602864. https://doi.org/10.2527/1995.73102860x.

Alves, A. C., N. G. Alves, I. J. Ascari, F. B. Junqueira, A. S. Coutinho, R. R. Lima, J. R. O. Pérez, S. O. De Paula, I. F. FurushoGarcia, and L. R. Abreu. 2015. Colostrum composition of Santa Inês sheep and passive transfer of immunity to lambs. J. Dairy Sci. 98:3706-3716. https://doi.org/10.3168/jds.2014-7992.

Bland, J. M., and D. Altman. 1986. Statistical methods for assessing agreement between two methods of clinical measurement. Lancet 327:307-310. https://doi.org/10.1016/S0140-6736(86)90837-8.

Bland, J. M., and D. Altman. 2003. Applying the right statistics: Analyses of measurement studies. Ultrasound Obstet. Gynecol. 22:85-93. https://doi.org/10.1002/uog.122.

Cartoni, G., F. Coccioli, R. Jasionowska, and M. Masci. 1999. Determination of cows' milk in goats' milk and cheese by capillary electrophoresis of the whey protein fractions. J. Chromatogr. A 846:135-141. https://doi.org/10.1016/S0021-9673(98)01032-2.

Ceniti, C., F. Trimboli, G. Massimini, V. M. Morittu, T. Gigliotti, C. Cicino, and D. Britti. 2016. Evaluation of immunoglobulin concentrations in ovine colostrum by routinely capillary electrophoresis instrument. Large Anim. Rev. 22:33-36.

Cifuentes, A., M. de Frutos, and J. C. Diez-Masa. 1993. Analysis of whey proteins by capillary electrophoresis using buffer-containing polymeric additives. J. Dairy Sci. 76:1870-1875. https://doi. org/10.3168/jds.S0022-0302(93)77519-0.

Constant, S. B., M. M. Leblanc, E. F. Klapstein, D. E. Beebe, H. M. Leneau, and C. J. Nunier. 1994. Serum immunoglobulin G concentration in goat kids fed colostrum or a colostrum substitute. J. Am. Vet. Med. Assoc. 205:1759-1762.

Demirören, E., J. N. B. Shrestha, and W. J. Boylan. 1995. Breed and environmental effects on components of ewe productivity in terms of multiple births, artificial rearing and 8-month breeding cycles. Small Rumin. Res. 16:239-249. https://doi.org/10.1016/09214488(95)00626-V.

Hernández-Castellano, L. E., A. Morales-delaNuez, D. SánchezMacías, I. Moreno-Indias, A. Torres, J. Capote, A. Argüello, and N. Castro. 2015. The effect of colostrum source (goat vs. sheep) and timing of the first colostrum feeding ( $2 \mathrm{~h}$ vs. $14 \mathrm{~h}$ after birth) on body weight and immune status of artificially reared newborn lambs. J. Dairy Sci. 98:204-210. https://doi.org/10.3168/jds.20148350.

Lérias, J. R., L. E. Hernández-Castellano, A. Suárez-Trujillo, N. Castro, A. Pourlis, and A. M. Almeida. 2014. The mammary gland in small ruminants: Major morphological and functional events underlying milk production-A review. J. Dairy Res. 81:304-318. https://doi.org/10.1017/S0022029914000235.

Lin, L. I. 1989. A concordance correlation coefficient to evaluate reproducibility. Biometrics 45:255-268.

Loste, A., J. J. Ramos, A. Fernandez, L. M. Ferrer, D. Lacasta, M. T. Verde, M. C. Marca, and A. Ortìn. 2008. Effect of colostrum treated by heat on immunological parameters in newborn lambs. Livest. Sci. 117:176-183. https://doi.org/10.1016/j.livsci.2007.12.012.

Massimini, G., A. Peli, A. Boari, and D. Britti. 2006. Evaluation of assay procedures for prediction of passive transfer status in lambs. Am. J. Vet. Res. 67:593-598. https://doi.org/10.2460/ ajvr.67.4.593.

Moretti, D. B., L. Kindlein, P. Pauletti, and R. Machado-Neto. 2010. IgG absorption by Santa Inês lambs fed Holstein bovine colostrum or Santa Inês ovine colostrum. Animal 4:933-937. https:// doi.org/10.1017/S1751731110000157.

Quigley, J. D., A. F. Carson, and J. Polo. 2002. Immunoglobulin derived from bovine plasma as a replacement for colostrum in newborn lambs. Vet. Ther. 3:262-269.

Ruby, R. E., C. C. Balcomb, S. A. Hunter, and K. E. Lawrence. 2012. Bovine colostrum-induced anaemia in a 2-week-old lamb. N. Z Vet. J. 60:82-83. https://doi.org/10.1080/00480169.2011.628634.

Stelwagen, K., E. Carpenter, B. Haigh, A. Hodgkinson, and T. T. Wheeler. 2009. Immune components of bovine colostrum and milk. J. Anim. Sci. 87:3-9. https://doi.org/10.2527/jas.2008-1377.

Swanson, T. J., C. J. Hammer, J. S. Luther, D. B. Carlson, J. B Taylor, D. A. Redmer, T. L. Neville, J. J. Reed, L. P. Reynolds, and J. S. Caton. 2008. Effects of gestational plane of nutrition and selenium supplementation on mammary development and colostrum quality in pregnant ewe lambs. J. Anim. Sci. 86:2415-2423. https://doi.org/10.2527/jas.2008-0996.

Winter, A. 2011. Bovine neonatal pancytopenia, and anaemia in lambs caused by feeding cow colostrum. Vet. Rec. 168:84 https://doi. org/10.1136/vr.d370.

Winter, A. C., and M. J. Clarkson. 1992. Farm investigations of anaemia in lambs caused by feeding cow colostrum. Vet. Rec. 131:213216. https://doi.org/10.1136/vr.131.10.213.

Zhu, M. D., R. Rodriguez, D. Hansen, and T. Wehr. 1990. Capillary electrophoresis of proteins under alkaline conditions. J. Chromatogr. 516:123-131. https://doi.org/10.1016/S0021-9673(01)90210-9. 